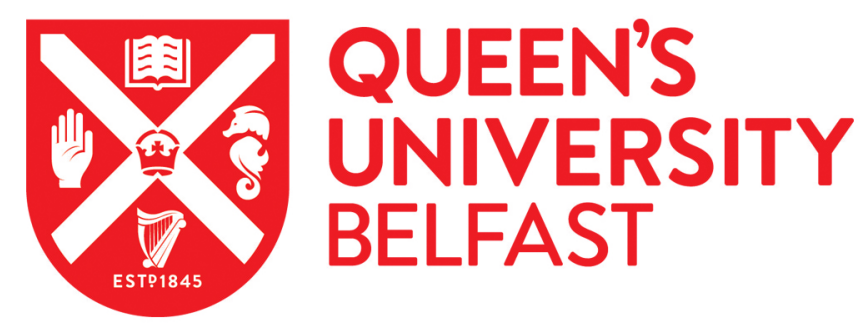

\title{
Investigating the effect of PID controller on inertial response in doubly fed induction generator (DFIG)
}

Ahmad, T., Littler, T., \& Naeem, W. (2016). Investigating the effect of PID controller on inertial response in doubly fed induction generator (DFIG). In 2016 UKACC 11th International Conference on Control (CONTROL) Institute of Electrical and Electronics Engineers Inc.. https://doi.org/10.1109/CONTROL.2016.7737562

Published in:

2016 UKACC 11th International Conference on Control (CONTROL)

Document Version:

Peer reviewed version

Queen's University Belfast - Research Portal:

Link to publication record in Queen's University Belfast Research Portal

Publisher rights

Copyright 2017 IEEE. This work is made available online in accordance with the publisher's policies. Please refer to any applicable terms of use of the publisher.

\section{General rights}

Copyright for the publications made accessible via the Queen's University Belfast Research Portal is retained by the author(s) and / or other copyright owners and it is a condition of accessing these publications that users recognise and abide by the legal requirements associated with these rights.

Take down policy

The Research Portal is Queen's institutional repository that provides access to Queen's research output. Every effort has been made to ensure that content in the Research Portal does not infringe any person's rights, or applicable UK laws. If you discover content in the Research Portal that you believe breaches copyright or violates any law, please contact openaccess@qub.ac.uk. 


\title{
Investigating the effect of PID controller on inertial response in doubly fed induction generator (DFIG)
}

\author{
Thelfa Ahmad ${ }^{1}$, Tim Littler ${ }^{2}$, Wasif Naeem ${ }^{3}$ \\ School of Electronics, Electrical Engineering and Computer Science \\ Queen's University Belfast, Belfast, UK \\ $\underline{\text { tahmad01@qub.ac.uk }}$, t.littler@qub.ac.uk ${ }^{2}, \underline{\text { w.naeem@.qub.ac.uk }}$
}

\begin{abstract}
The increasing penetration of wind generation impacts the reliability and stability of power systems. This paper investigates and analyses the effect of PID controller parameters on the inertial response of a doubly fed induction generator (DFIG) wind turbine to support the frequency control of a power system in the event of sudden power changes. The goal of this review is to extensively determine the effect of PID parameters to compare and set a benchmark so that an adaptive control strategy can be developed for frequency regulation. A conventional inertial controller algorithm using the rate of change of frequency (RoCoF) and frequency deviation loops was investigated whilst the contribution of the DFIG to system inertial response and frequency control are examined. The paper considers the influence of supplementary inertial control loop parameters on the inertial response and power system frequency. The results indicate that the DFIG inertial controller scheme is able to provide appropriate frequency support.
\end{abstract}

Keywords-wind energy generation; doubly-fed induction generator (DFIG); frequency control; inertia; kinetic energy; rate of change of frequency $(\mathrm{RoCoF})$.

\section{INTRODUCTION}

The challenge and necessity of a reduction in $\mathrm{CO} 2$ emissions due to climate change concerns, as well as security and shortage of supplies such as fossil fuels, has meant that many countries have made commitments to increase the penetration of non-conventional and renewable generation, thus displacing centralized generation from traditional fuel sources, such as coal, oil and gas. Large-scale integration of alternate energy sources, although beneficial, can have unpredictable consequences which can challenge the stability of existing power systems, not least with widespread integration of wind power generation. In an electric power system, electrical generation must meet expected power demand and as such, power supply must be continuously balanced: power imbalance occurs as a result of mismatch between generation and load. Consequently, frequency change will arise and consideration of the RoCoF in particular is important because it is a problem that can lead to additional losses of generation and increase the risk of a potential system collapse. Though minor mismatches exist on the grid, a significant imbalance in either magnitude or time span can be catastrophic for power systems, possibly resulting in black-out or equipment damage. The major advantages of wind energy include sustainability, minimal $\mathrm{CO} 2$ impacts, and a more reliable source in comparison with other renewable energy resources. Wind energy has developed rapidly over the last 25 years and is one of the most prominent renewable sources of electricity across the world [1].

Recently there has been an increased interest in doubly fed induction generator (DFIG) based wind turbines due to their wider operating range and efficiency across a range of wind velocities. Thus they are capable of a delivering power output at different wind speeds [2] . Many of the large wind turbines that are now commercially available are DFIG units. Operating a large number of DFIG based wind turbines can displace conventional synchronous generation and this in turn creates a range of new problems such as reducing system inertia and increasing the potential for greater RoCoF. In effect, this reduces the ability to control the frequency of the system due to the fact that the DFIG control system decouples the mechanical and electrical systems, thus preventing the generator from responding to system frequency changes. This is undesirable when there are a large number of DFIG wind turbines operating, especially in periods of low load and on smaller power systems (e.g., Ireland) [3].

The frequency of a power system with low inertia will certainly change rapidly for abrupt variations in generation or load, which reduces the control margin for system frequency. Therefore, modern variable speed wind turbines (VSWTs) do not participate in control of the system frequency. However, this problem should be solved properly to ensure reliable and stable operation of the power grid.

Since the PID is an implicit element of DFIGs, this paper provides a timely review of the role of this controller in preserving inertia. This study therefore provides an investigation of the effect of the proportional-integralderivative (PID) controller parameters on system inertial response. Section 1 analyses the benefits of the fast response capability of a DFIG with no supplementary inertial control in the power control loop. With a supplementary loop added to the standard power control loop, the DFIG is shown to exhibit inertial response. The influence of controller parameters for different values is investigated in Section 2. Section 3 compares the RoCoF and frequency deviation loops based on their effect on system frequency and the DFIG wind turbine. Literature published to date indicates that limited work has investigated the effect of changing controller parameters. However this paper concludes that significant performance 
improvement can be made by appropriate adjustment of inertial controller parameters.

\section{FREQUENCY CONTROL}

The purpose of any control system is to maintain the output of a system at a specified value. In the case of power system frequency control, the objective is to tightly govern this primary parameter close $(+/-1 \%)$ to the nominal frequency (49.5 - 50.1, UK), [1]. Network frequency will change when the total active power generation differs from the total active power required by the load in the network. The system frequency is controlled by balancing the generation of power against load demand on a second-by-second basis. Conventional power plant with synchronous generation has the inherent capability to control the frequency, because it has a significant inertia constant [4].

The response duties of a conventional power plant can be split into primary and secondary responses. The primary and secondary responses are defined as the additional active power delivered by automatic governor action from a generating unit that is available at 10 seconds and 30 seconds, respectively after the event and which can be sustained for 20 seconds to 30 minutes [5]. Frequency deviations of $<0.05 \mathrm{~Hz}$ are usually considered small although these could be significant depending on interconnection and operating conditions. The IEEE recommends that frequencies within $\pm 0.036 \mathrm{~Hz}$ around the nominal frequency be considered as nominal [6].

Usually wind turbines operate to maximize their output power under all possible conditions. Consequently the DFIG cannot provide any further increase in active power output and therefore participate in secondary response services of frequency deviation which conventional generators can do. However, a DFIG can provide transient primary frequency control in the interconnected power system by utilizing the kinetic energy in the inertia of DFIG [7].

\section{PID CONTROLLER}

A PID controller is by far the most common control algorithm feedback loop in practice. The controller takes a measured value from a process or other apparatus and compares it with a reference set point value. The difference (or "error" signal) is then used to adjust some input to the process in order to bring the process ("measured") value back to its desired set point. The PID controller adjusts the process output based on the history (integral) and rate of change (derivative) of the error signal, which gives more accurate and stable control [8]. In the following, a brief discussion of each of the three PID terms is provided from the perspective of application to a power system.

\section{A. Derivative Term:}

The derivative action predicts system behavior and thus improves settling time and stability of the system. The magnitude of the contribution of the derivative term to the overall control action is represented by the derivative gain, $K d$ [8]. This slows the rate of change of the controller output and therefore reduces the magnitude of the overshoot (produce by the integral action). The effect of $K d$ is most noticeable close to the controller set point.

In power systems, the derivative term acts to increase the decelerating torque of the wind turbine rotor speed (proportional $d f / d t$ ) to reduce rate-of-change of frequency and improve the stability. This control induces a temporary wind turbine inertial response and makes the wind turbine respond to frequency disturbances. The additional power output $(P)$ from the kinetic energy $(E)$ of DFIG wind turbine can be written as, [3],

$$
P=\frac{d E}{d t}=J w \frac{d w}{d t}
$$

where $P, E, J$ and $w$ represent additional power output of the wind turbine, the kinetic energy stored in the rotating mass of the wind turbine, the moment of inertia of the wind turbine and the rotational speed of DFIG, respectively.

When there is a reduction in the power system frequency from its operating value, the speed of the generator starts to drop. This can be considered as a deceleration torque $T_{\text {dec }}$, acting on the on the rotating mass. The rotor speed of the DFIG can usually vary between $0.8 \mathrm{p} . \mathrm{u}$ and $1.2 \mathrm{P}$.u. The kinetic energy from the rotating mass of wind turbine is released rapidly through the power electronic converter. The decelerating torque can be constructed by differentiating the kinetic energy $\left(1 / 2 J w^{2}\right)$ released by the mass and then by dividing the equivalent power by the rotation speed $w$. Therefore the decelerating torque is proportional to $d w / d t$ and thus to $d f / d t$. This reduces the rate of change of frequency and helps increase the frequency nadir [9].

\section{B. Proportional Term:}

A higher proportional controller gain $(K p)$ will have the effect of reducing the rise time and will reduce but never eliminate the steady-state error. As the gain is increased, the response will become faster but at the cost of higher overshoot in the output response [8].

In power systems, this controller represents the governor or droop control. This control strategy is similar to the primary frequency control used in conventional generators. The amount of additional active output power produced by the wind turbine is proportional to the difference between the measured and the nominal frequency. The droop controller regulates the active power output and greatly improves the frequency nadir and also the frequency recovery process following a disturbance [10].

\section{Integral Term:}

The contribution from the integral term is proportional to both the magnitude and duration of the error. The integral term accelerates the movement of the process towards the set point and eliminates the residual steady-state error that occurs with a purely proportional controller [8]. The optimal speed of the non-conventional generator, after the transition period is over, can be regained by using a PI controller. The constants $(K p$, $K i$ ) of a PI controller should be chosen in order to allow fast speed recovery with a shorter period of transition variation 
[11]. By contribution in the frequency regulation, in case that the speed is admit to decrease for longer event, then the wind turbine machine may come in to the stage of stalling. Therefore, when the power system frequency reaches a new steady state that is marginally less than normal value, the frequency deviation is controlled by the load damping as well as generator's speed-droop results. The integral term is outside the scope of this work and is not considered here.

\section{THE INERTIAL CONTROLLER}

From the viewpoint of a power system, the inertia is the resistance to changes in the system frequency. Inertial response is the reduction in the rate of change of frequency obtained when the stored kinetic energy is released which is the energy stored in the rotating mass of the generators given by (1).

$$
E=\frac{1}{2} J w_{r}^{2}
$$

Where $J$ is the inertia of the generator in $K_{g} . m^{2}$ and $w_{r}$ is its rotational speed in $\mathrm{rad} / \mathrm{s}$.

In conventional power systems, a constant inertia $H$ in seconds is the maximum time that the generator can provide full output power from its own stored kinetic energy typically in the range of 2-9 seconds [2].

Constant inertia $H$ is defined by (2).

$$
H=\frac{J w_{r}^{2}}{2 S}
$$

Where $S$ is the nominal apparent power in MVA of the generator [2], [12]. The moment of inertia does not cause power imbalance but it does affect the system's response to those disturbances and the frequency control methodology used to recover from these disturbances. A significant amount of research on inertial controller has been carried out to regulate the frequency of a power system. The basic form of inertial control loop involves using the RoCoF [3], [4]. The RoCoF and frequency deviation loops were used to improve the frequency support of DFIG [9], [13], [14]. When the system frequency changes e.g. due to generator tripping or sudden increase in load, the output active power of DFIG should respond to it quickly through the supplementary inertia controller. The inertial controller for the DFIG-based wind turbine works as follows. When the power system frequency drops below its nominal value for any disturbance such as sudden increase in load, the inertial response control loop (the active power reference generated by the RoCoF loop $\Delta P_{\text {in }}$ and active power reference generated by the frequency_deviation loop $\Delta P$ ) sends additional active power $\Delta P_{\text {ref }}$ to the DFIG active power reference $P_{\text {ref }}$ control loop as shown in Fig.1. Therefore, $\Delta P_{\text {ref }}$ become positive and consequently $P_{r e f}$ increases. Thus, the kinetic energy stored in the rotating mass in the DFIG is released and consequently the rotor speed of DFIG $w_{r}$ decreases according to (3) [2].

$$
P_{m}-P_{e}=P_{m}-\left(P_{M P P T}+\Delta P+\Delta P_{i n}\right)=J w_{r} \frac{d w_{r}}{d t} \ldots \ldots
$$

Where $P_{m}, P_{e}, P_{M P P T}$ represents mechanical power electromagnetic power and maximum power point tracking respectively.

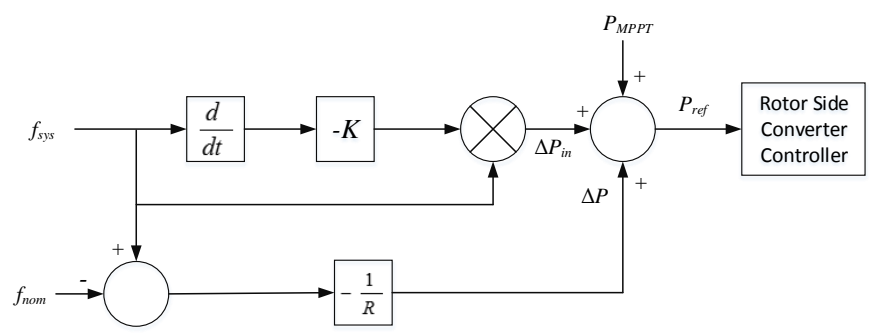

$f_{\text {sys }}, f_{\text {nom }}$ : system frequency and nominal frequency

$R$ : droop gain of the loop

Fig. 1 Inertial controller schematic for the DFIG [15]

\section{SIMULATION STUDIES}

Simulations have been carried out in Matlab/Simulink to validate the inertial controller scheme and to illustrate the capability of DFIG to simulate system inertia in case of any disturbance such as sudden increase in load. A four machine power grid is used, which consists of three conventional power plants (M1, M2, M3), two combined loads (L1, L2) and a DFIG-based wind farm rated at $300 \mathrm{MW}$ (1.5 MW each). The M1, M2, M3 are rated at $400 \mathrm{MW}, 400 \mathrm{MW}$ and $500 \mathrm{MW}$ respectively whereas the two loads $\mathrm{L} 1$ and $\mathrm{L} 2$ are rated at 800 MW each. The wind speed is assumed to be $12 \mathrm{~m} / \mathrm{s}$ whilst the DFIG is originally under the MPPT control.

CASE STUdy 1: Comparative study of the DFIG inertial response with and without inertial controller

\section{A. DFIG with no inertial controller}

In this case, the load increased by $10 \%$ at $\mathrm{t}=50 \mathrm{~s}$, as a consequence of the power imbalance (the generation power against the load demand). This causes changes in the power system frequency.

The system frequency drop is shown in Fig. 2(a). Since there is no additional inertial control added to the power control loop, the rotor mechanical speed is decoupled from the grid frequency. As a result, the DFIG showed no or minimal inertia and the power system frequency rapidly drops to around $59.5541 \mathrm{~Hz}$. The increased load is eventually compensated by the conventional plant. However, system frequency then overshoots to around $59.8398 \mathrm{~Hz}$ due to the integral gains of the speed controllers in the conventional generators. 


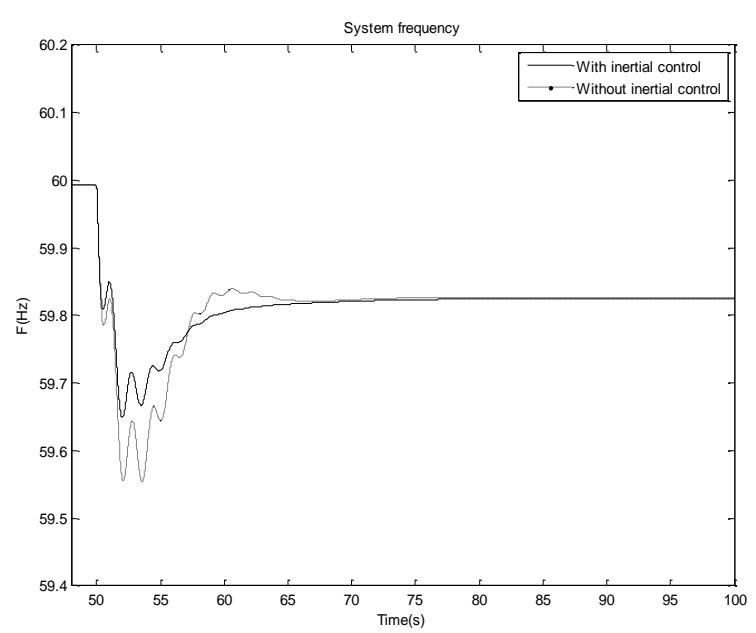

(a) Power system frequency

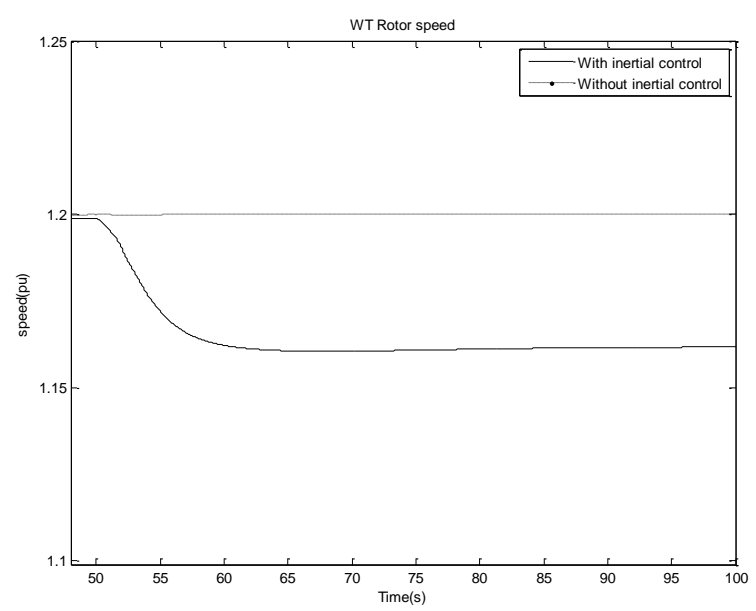

(b) Rotor speed variation

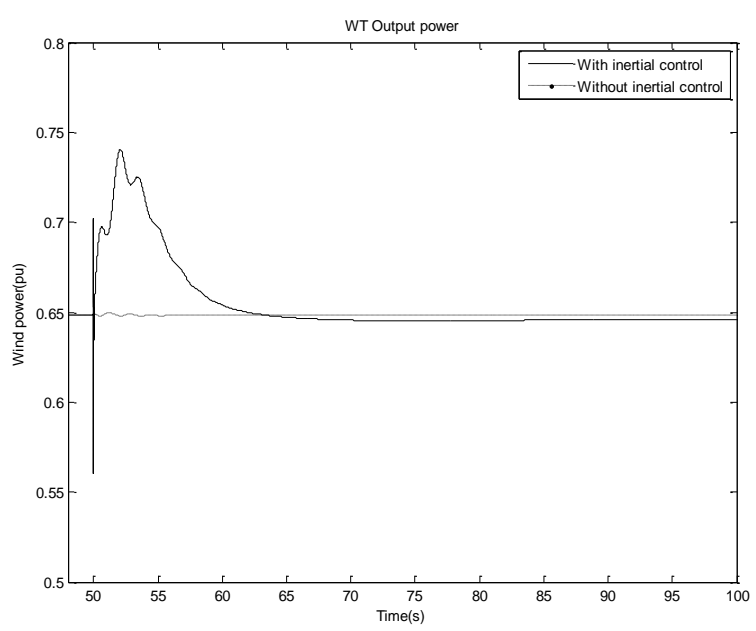

(c) DFIG active power output

Fig.2 Inertia response of DFIG with and without inertial control

Without any inertial control on the wind power plant, the rotor speed remains constant and also the active power of the DFIG remains constant at $0.6482 \mathrm{pu}$ as the conventional generators increased their generation to stabilize the effect of additional loading as shown in Figs. 2(b) and 2(c).

\section{B. Inertial response of the DFIG}

Similar to case A, the load is increased suddenly from 1600 MW to $1760 \mathrm{MW}$ at 50s. An additional inertial control now is introduced to the power control loop. It can be noticed from Fig. 2 that when the system frequency decreases, an additional power $\Delta P_{r e f}$ is added to the active power reference $P_{r e f}$, by increasing the torque set points of the DFIG wind turbine thus raising the electromagnetic torque. As the wind speed is constant, mechanical torque remains unchanged, whilst the rotor decelerates as shown in the torque equation below, [2]:

$$
T_{m}-T_{e}=J \frac{d w_{r}}{d t}
$$

Therefore, kinetic energy will be released in this situation. Fig. 2(a), depicts that the system frequency nadir is improved from 59.5541 to $59.6468 \mathrm{~Hz}$, because of the sudden increase in the electrical active output power. Since the DFIG mechanical torque power is smaller than its electromagnetic torque power, the rotor speed will decrease as shown in Fig. 2(b). In Fig. 2(c), The DFIG increases its output active power from 0.6482 to $0.74 \mathrm{Pu}$. In summary, as can be observed, without support from wind generation, the frequency response has a significant drop, the inertial control improves the frequency nadir whilst reducing this frequency decrement rate. If the frequency continues to drop, and if the electromagnetic power remains larger than the mechanical power then the wind turbine will stall. Therefore, in power systems where frequency changes considerably, the DFIG stator output active power should be actively controlled so as not to cause wind turbine stall.

CASE STUDY 2: The effect of controller parameters of DFIG on inertial response during the transient event.

\section{A. Influence of inertial controller parameter, Kd (RoCoF loop) on inertial response.}

Fig. 3 represents the influence of the controller parameter $(K d)$ on the system's response using the RoCoF loop. When the load increases at $t=50 \mathrm{~s}$, power system frequency drops as shown in Fig. 3(a) which also illustrates frequency responses for different values of $K d$. As the gain, $K d$ increases, the RoCoF becomes effectively smaller and the frequency nadir increases slightly as given in Table 1 thus improving frequency regulation. At the same time, the rotor speed reduces whilst the inertial response increases as depicted in Figs. 3(b) and 3(c). However, in this case, the total energy released is less as compared to when both RoCoF and frequency deviation loops were simultaneously employed (see Case Study 3 for further explanation). From Fig. 3(c), it can be observed that at $t=53.9 \mathrm{~s}$, the active output power of the DFIG wind turbine continues to decrease rather than reverting back to its normal operation. Therefore any power that is temporarily awarded to the grid is recovered later to bring the 
rotor speed back to its optimal value. In other words, only a part of the accessible aerodynamic power is transmitted to the grid. In addition, the reduction in power causes a decline in the system frequency after $t=53.9 \mathrm{~s}$ as shown in Fig. 3(a). In summary, it can be concluded that for a single loop inertial controller, the higher the value of $K d$ is, the better the power system frequency becomes.

\section{B. Influence of the droop controller (frequency deviation loop) parameter, $\mathrm{Kp}$ on the inertial response}

Fig. 4 depicts the influence of controller parameter $K p$ on the inertial response. The power system frequency for different values of $K p$ is shown in Fig. 4(a) which clearly illustrates the improvement in the frequency regulation as $K p$ increases. Moreover, as the gain value $K p$ increases, power system frequency will have less overshoot. The steady state error is also decreased, as expected, whilst $K p$ is increased. The frequency nadir, when $K p=5$ is $59.5822 \mathrm{~Hz}$ as compared to the $59.6486 \mathrm{~Hz}$ when $K p=20$ (see Table 2). Therefore the frequency deviation loop controller gain, $K p$ has a great effect on the frequency nadir. As $K p$ increases, the rotor speed decreases further (see Fig. 4(b)) and the wind turbine provides more kinetic energy as shown in Fig. 4(c) and Table 2. In summary, it can be observed, that for a larger value of $K p$, the frequency regulation improves and the frequency nadir increased, however the drop in the rate of change of frequency is nearly the same.

CASE STUDY 3: The implementations of DFIG wind turbines inertial controller

\section{A. Single loop inertial controller}

Fig. 5(a) illustrates the power system frequency underfrequency event. In the case of the (single loop) inertial controller, the frequency drops to $59.5782 \mathrm{~Hz}$ relative to $59.5541 \mathrm{~Hz}$ without any control action from the wind turbine. The RoCoF $(d f / d t)$ controller works when there is a change in frequency and has a significant effect on the RoCoF due to the faster release of kinetic energy resulting from its proportional relationship to the derivative of the power system frequency thus reducing the RoCoF as shown in Fig. 5(d). However, the improvement in frequency nadir is rather small. In general, the single loop inertial controller is able to support the system frequency by decreasing the RoCoF but there is a room for the frequency nadir to be improved using a combination of RoCoF and droop loops as presented in the following.

\section{B. Double-loop inertial controller}

The frequency deviation loop controller plays a valuable role when there is a significant increase or decrease in the power system frequency. From Fig. 5, it can be observed that the inertial control algorithm of the DFIG that employs both loops has a greater effect than a single loop inertial controller. The frequency drops to $59.6486 \mathrm{~Hz}$ (Fig. 5(a)) compared to $59.5782 \mathrm{~Hz}$, in the case of a single loop.

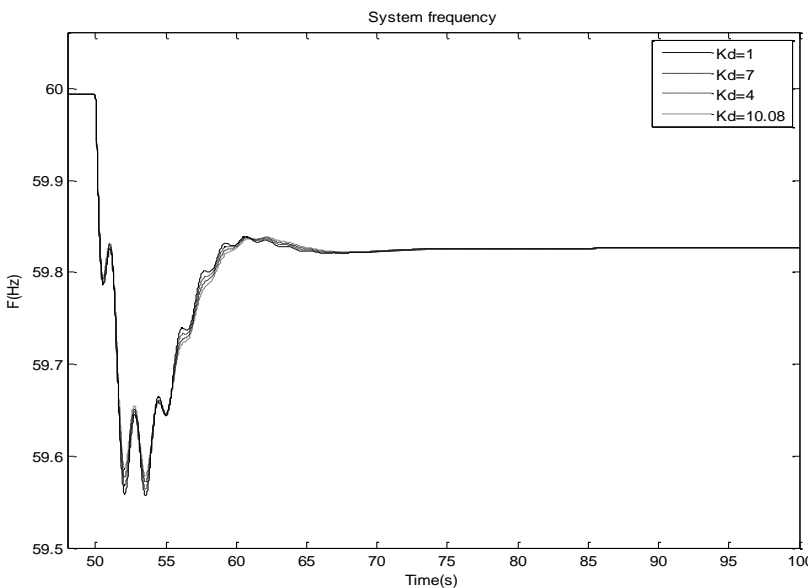

(a) Power system frequency

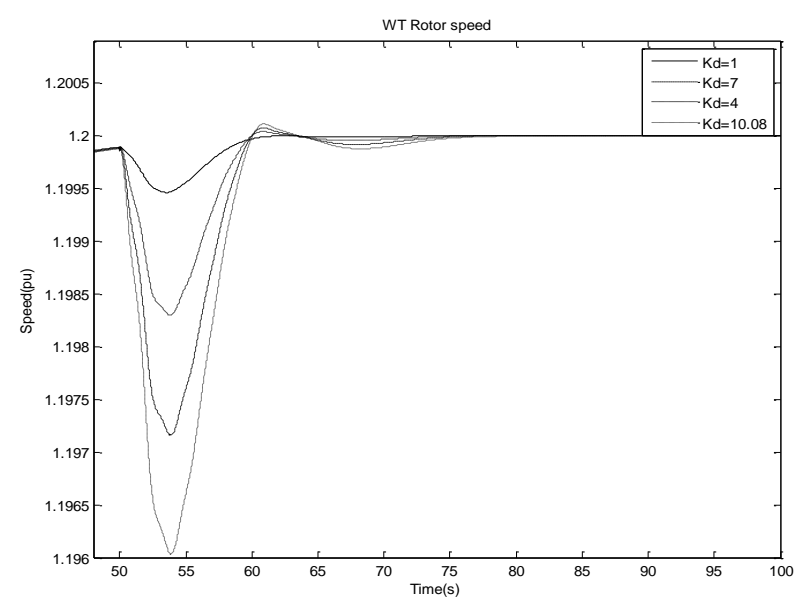

(b) Rotor speed variation

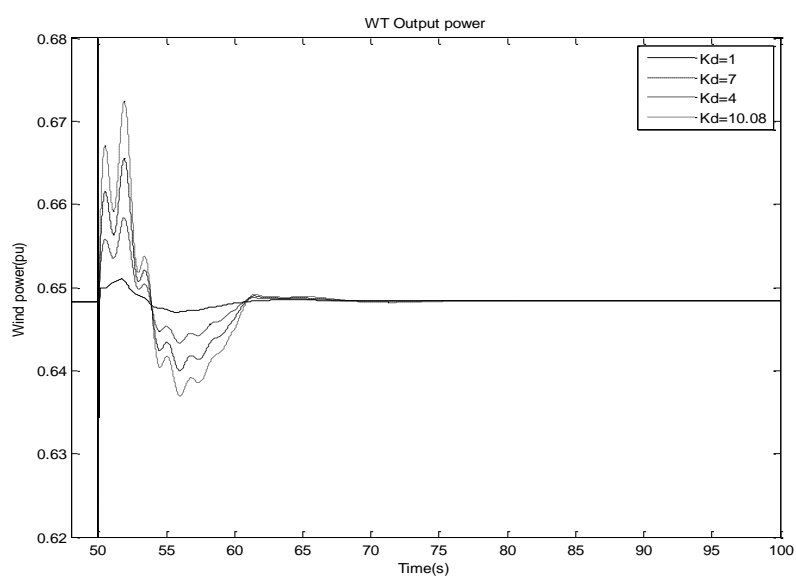

(c) DFIG active power output

Fig. 3 Inertial response of DFIG for different gain value of $K d$ 
Table. 1 Inertial response, frequency nadir and rotor speed value for different values of control gains $(K d)$

\begin{tabular}{|c|c|c|c|c|c|}
\hline No & Kd & $\begin{array}{c}\text { Steady } \\
\text { state } \\
\text { error }\end{array}$ & $\begin{array}{c}\text { Inertial } \\
\text { response }\end{array}$ & $\begin{array}{c}\text { Frequency } \\
\text { nadir }\end{array}$ & $\begin{array}{c}\text { Rotor speed } \\
\text { (min value) }\end{array}$ \\
\cline { 2 - 6 } & & $(\mathbf{H z})$ & $(\mathbf{p u})$ & $(\mathbf{H z})$ & $(\mathbf{p u})$ \\
\hline 1 & 0.5 & -0.4446 & 0.6502 & 59.5554 & 1.1995 \\
\hline 2 & 1 & -0.4433 & 0.651 & 59.5567 & 1.1995 \\
\hline 3 & 4 & -0.4359 & 0.6584 & 59.5641 & 1.1983 \\
\hline 4 & 7 & -0.4288 & 0.6655 & 59.5712 & 1.1972 \\
\hline 5 & 10.08 & -0.4218 & 0.6724 & 59.5782 & 1.196 \\
\hline
\end{tabular}

The frequency nadir is raised significantly higher by the double-loop inertia controller. Thus, the inertial control with a frequency deviation loop, extensively enhances the frequency nadir as seen in Fig. 5(a). This increment in the frequency nadir is a result of the fact that greater total output power is released when both loops are used although, it does not have a significant impact on the RoCoF as shown in Fig. 5(d). Moreover, the oscillations and overshoot are damped, as compared to the single loop controller. Therefore, both RoCoF loop and frequency deviation loop were applied to support system frequency which has a positive effect when power system frequency deviation increases. Thus this method is broadly adopted for DFIG-based wind turbines. On the other hand, the implementation of the double-loop controller considerably improves the frequency nadir. This approach can effectively results in greater inertial response as shown in Fig. 5(c). It cancels the accelerating torque in order to restore the inertia response by increasing the torque deceleration. However, by cancelling the torque acceleration, the machine will operate at a reduced speed. Thus the wind turbine is forced to operate away from the maximum power extraction curve. Finally, as mentioned earlier, the operating speed of the DFIG would need to revert back to its optimal value during the tertiary response [9].

\section{CONCLUSIONS}

This paper investigated and analysed the transient performance of DFIG wind turbines for frequency regulation in power systems. It can be learned from the results that DFIG wind turbines have the capability to support the system frequency and to emulate the inertia by adding supplementary controllers in the power electronic convertor of DFIG wind turbine machine. The frequency deviation loop gain, $K p$ and the derivative constant, $K d$ together have a significant influence on the inertial response and the operational robustness. Therefore, these controller parameters should be designed and chosen in order to allow the DFIG wind turbine to participate in supporting the system frequency.

Also, the results demonstrate that the RoCoF loop controller has the ability to reduce the RoCoF. However, it only slightly improves the frequency nadir. It has been shown that when both RoCoF and droop loops are employed simultaneously, the frequency nadir improves significantly. Therefore, a combination of RoCoF and frequency deviation loops are widely adopted in DFIGs to support system frequency.

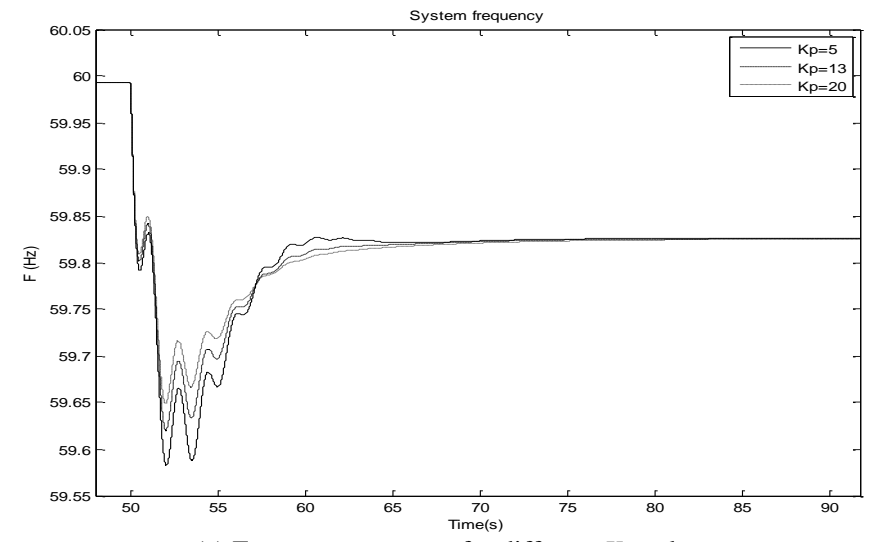

(a) Frequency response for different $K p$ values

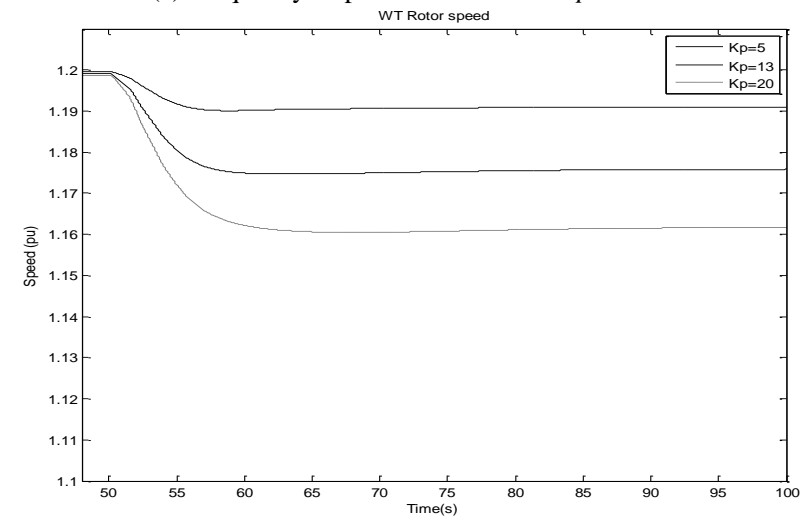

(b) Rotor speed variation

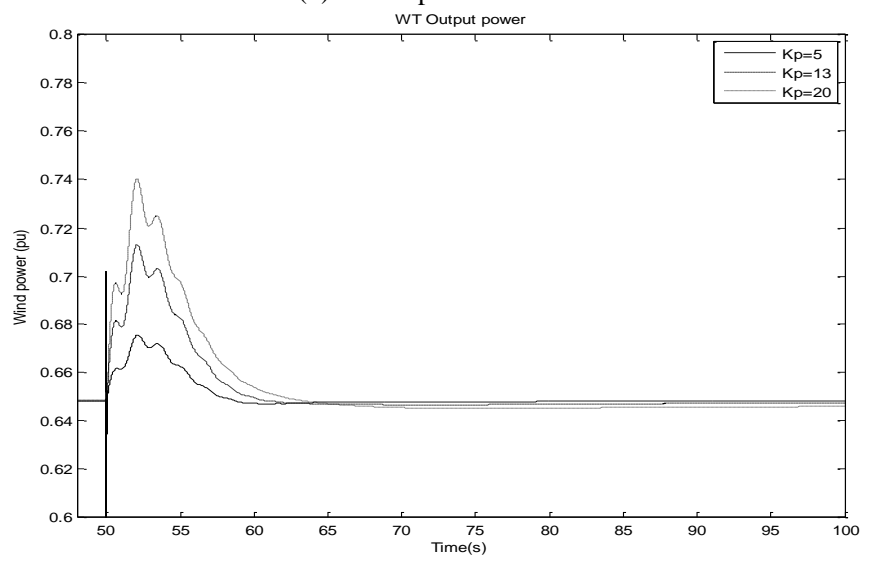

(c) Wind turbine active power

Fig. 4 Influence of controller parameters $\mathrm{Kp}$ on inertial response.

Table.2 Inertial response, frequency nadir and rotor speed value for different values of controller gains $(K p)$ of DFIG

$$
(K d=10.08)
$$

\begin{tabular}{|c|c|c|c|c|c|}
\hline No & \multirow{2}{*}{ Kp } & $\begin{array}{c}\text { Steady } \\
\text { state } \\
\text { error }\end{array}$ & $\begin{array}{c}\text { Inertial } \\
\text { response }\end{array}$ & $\begin{array}{c}\text { Frequency } \\
\text { nadir }\end{array}$ & $\begin{array}{c}\text { Rotor } \\
\text { speed } \\
\text { (min value) }\end{array}$ \\
\cline { 2 - 6 } & $\mathbf{( H z )}$ & $\mathbf{( p u )}$ & $\mathbf{( H z )}$ & $\mathbf{( p u )}$ \\
\hline 1 & 5 & -0.4178 & 0.6756 & 59.5822 & 1.1901 \\
\hline 2 & 9 & -0.3981 & 0.6953 & 59.6019 & 1.1824 \\
\hline 3 & 13 & -0.3800 & 0.7132 & 59.62 & 1.1747 \\
\hline 4 & 18 & -0.3592 & 0.7332 & 59.6408 & 1.1646 \\
\hline 5 & 20 & -0.3514 & 0.7405 & 59.6486 & 1.1605 \\
\hline
\end{tabular}




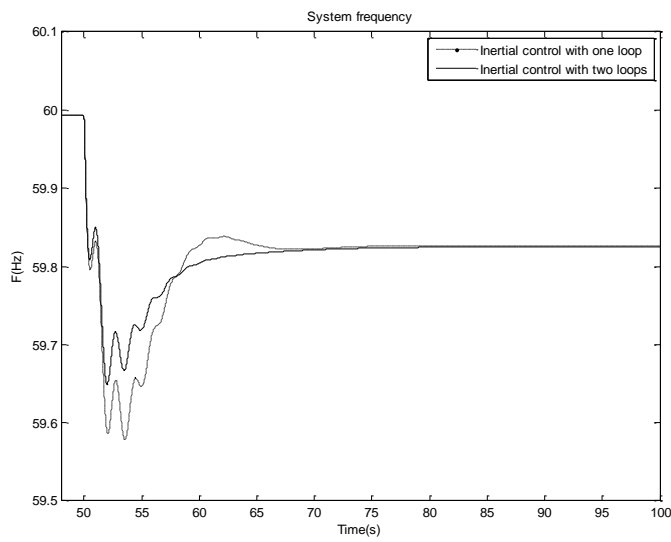

(a) Power system frequency

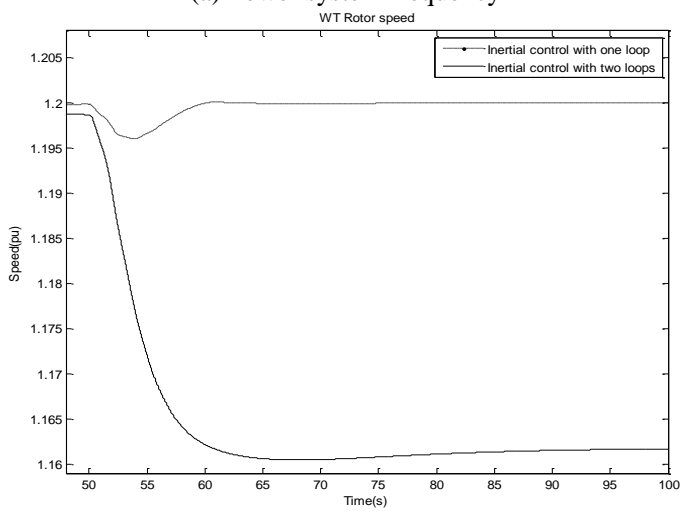

(b) Rotor speed variations

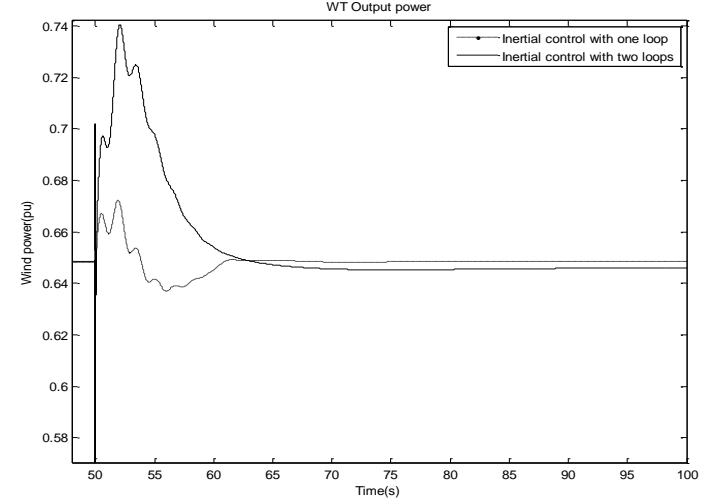

(c) DFIG active power output

\section{ACKNOWLEDGEMENT}

The first author would like to acknowledge the financial support provided by the Department of Employment and Learning, Northern Ireland to carry out this research.

\section{REFERENCES}

[1] M.A. Hanley, "Frequency instability problems in north American interconnections," National Energy Technology Laboratory (United States) 2011

[2] B. Fox, Wind power integration: connection and system operational aspects, Iet, 2007.

[3] J. Ekanayake and N. Jenkins, "Comparison of the response of doubly fed and fixed-speed induction generator wind turbines to changes in network frequency," Energy Conversion, IEEE Transactions on, vol. 19 , no. 4, pp. 800-802 2004.

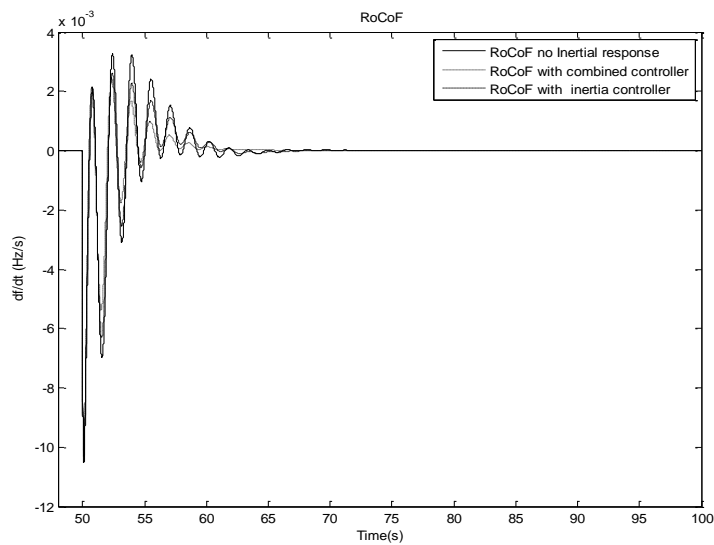

(d) $\mathrm{RoCoF}$

Fig. 5 Interial response of DFIG with single and double loop

[4] J. Ekanayake, L. Holdsworth and N. Jenkins, "Control of DFIG wind turbines," Power Engineer, vol. 17, no. 1, pp. 28-32 2003

[5] Holdsworth, L., ekanayake, J. B. and jenkins, N. (2004), power system frequency response from fixed speed and doubly fed induction generator-based wind turbines. Wind energy. 7: 21-35. doi: 10.1002/we.105,"

[6] P. Alto, "EPRI Power System Dynamics Tutorial, Final Report," THE ELECTRIC POWER RESEARCH INSTITUTE, INC. (EPRI), California, Rep. 1016042, July 20092009.

[7] I. Moore and J. Ekanayake, "Frequency response from wind turbines," in 2009 44th International Universities Power Engineering Conference (UPEC), 2009.

[8] W.C. Messner, D.M. Tilbury and A.P.R. Hill, Control Tutorials for MATLAB® and Simulink®, Addison-Wesley, 1999.

[9] G. Ramtharan, J.B. Ekanayake and N. Jenkins, "Frequency support from doubly fed induction generator wind turbines," Renewable Power Generation, IET, vol. 1, no. 1, pp. 3-9 2007.

[10] M. Kayikci and J.V. Milanović, "Dynamic contribution of DFIG-based wind plants to system frequency disturbances," Power Systems, IEEE Transactions on, vol. 24, no. 2, pp. 859-867 2009.

[11] J.M. Mauricio, A. Marano, A. Gómez-Expósito and J.L.M. Ramos, "Frequency regulation contribution through variable-speed wind energy conversion systems," Power Systems, IEEE Transactions on, vol. 24, no. 1, pp. 173-180 2009.

[12] O. Dudurych and M. Conlon, "Impact of reduced system inertia as a result of higher penetration levels of wind generation," in Power Engineering Conference (UPEC), 2014 49th International Universities, Cluj-Napoca; Romania, 2014, pp. 1-6.

[13] J. Morren, S.W.H. de Haan, W.L. Kling and J.A. Ferreira, "Wind turbines emulating inertia and supporting primary frequency control," Power Systems, IEEE Transactions on, vol. 21, no. 1, pp. 433-434 2006.

[14] Z. Zhang, Y. Sun, J. Lin and G. Li, "Coordinated frequency regulation by doubly fed induction generator-based wind power plants," IET Renewable Power Generation, vol. 6, no. 1, pp. 38-47 2012.

[15] H. Lee, J. Kim, D. Hur and Y.C. Kang, "Inertial control of a DFIGbased wind power plant using the maximum rate of change of frequency and the frequency deviation," Journal of Electrical Engineering and Technology, vol. 10, no. 2, pp. 4962015. 